\title{
Incidentes Procedimentais Na Busca e APreENSÃo: PRÉVia INSTAURAÇÃo do INQUÉrito E CAPACIDADE PARA REPRESENTAR PELAS MEDIDAS CAUTELARES
}

Rodrigo Carneiro Gomes

Polícia Federal - Brasil

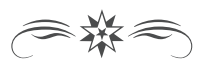

RESUMO

A diligência policial de cumprimento de mandado de busca e apreensão deve observar normas legais, atos normativos e a experiência adquirida no cotidiano, com preservação dos direitos e garantias do cidadão. É indispensável a prévia instauração de inquérito policial para execução das medidas cautelares de busca e apreensão e cabe ao Delegado de Polícia o poder de atuar perante o Poder Judiciário.

Palavras Chave: Busca e apreensão. Requisitos. Prisão em flagrante. Dispensabilidade do mandado de prisão. Delegado de Polícia. Requerimento.

\section{O InQuérito Policial e a Estigmatização da Busca e Apreensão em Órgãos Públicos e Escritórios Profissionais}

O inquérito policial é investigação preliminar administrativa, de natureza formal, inquisitivo, sigiloso (art. 20 do CPP), escrito (art. $9^{\circ}$ do CPP), oficioso (art. $5^{\circ}$., inciso I do CPP) e indisponível (art. 17 do CPP). Essas características comportam uma série de anotações e excepcionalidades, considerando que a mitigação da formalidade não gera prejuízo para a instrução e acontece, especialmente, para promoção da sua celeridade. $\mathrm{O}$ sigilo não pode ser oposto para o advogado regularmente constituído (Súmula vinculante $\mathrm{n}$. 14/STF e art. $7^{\circ}$, inciso XIV, $\$ 11$ da Lei n. 8.906/1994) e há inúmeras iniciativas para processamento do inquérito policial eletrônico e não mais por escrito. Até mesmo a propalada inquisitoriedade do inquérito policial tem cedido espaço a intervenções do investigado e da vítima em nome da apuração da verdade real e do enaltecimento do valor das provas colhidas. 
De qualquer forma, por mais que se confunda a formalização de atos de polícia judiciária com burocracia no inquérito, é da lei a sua forma escrita o que: a.) garante ao investigado e seu advogado o acesso aos autos da investigação; b.) confere transparência pré-processual; c.) registra a sequência cronológica de atos e a cadeia de custódia de provas; $\mathrm{d}$.) demonstra o procedimento de indicação de autoria e materialidade a serviço da busca da verdade real, e não apenas como subsídio da ação penal, que pode não haver por atipicidade ou inexistência do fato, por exemplo; e.) a portaria inicial, subscrita pelo Delegado de Polícia, mencionará a delimitação do fato, sua tipicidade penal e possível autoria.

\section{Para Perazzoni e Silva (2015, p. 87):}

(...) a investigação criminal realizada através do inquérito e sobo paradigma garantista esposado na $C F / 88$, não pode nem deve buscar exclusivamente confirmar a tese acusatória, muito pelo contrário: deverá, primordialmente, busca verificar a plausibilidade da imputação evitando processos desnecessários.

Nesse sentido, aliás, é importante lembrar que, apesar do caráter inquisitivo do inquérito, a legislação sabiamente autoriza à defesa e ao investigado diversas possibilidades de interferir e participar ativamente no curso das investigaçóes no sentido de produzir provas que lhe possam ser úteis à sua defesa.

A diligência policial de busca e apreensão, sempre autorizada judicialmente, ressalvada a situação flagrancial, tem ocorrido, com maior frequência do que antes, em locais como repartições públicas e escritórios de profissionais liberais.

A diligência policial é, por natureza, ostensiva e, claro, apesar da ostensividade que lhe é inerente, a discrição, independentemente de consignação no mandado judicial, deve ser a regra. A natureza ostensiva do trabalho policial, que imprescinde de coletes balísticos, armamento, viaturas e multiplicidade de atores, para a segurança da equipe e do investigado, não é bem compreendida, principalmente por estigmas (BACILA, 2005, pp. 45-46) em relação à atividade policial: "eu sou muito digno para receber a polícia em minha casa ou local de trabalho" ou "a polícia não pode 'invadir' uma repartição pública, escritório ou residência oficial, porque é uma afronta à toda categoria ou ao órgão". 
Conforme diretrizes contidas no art. 12 da Declaração dos Direitos do Homem e do Cidadão "A garantia dos direitos do homem e do cidadão necessita de uma força pública. Esta força é, pois, instituída para fruição por todos, e não para utilidade particular daqueles a quem é confiada”. A ostensividade que decorre do socorro à força pública inibe, ou pelo menos minimiza, a possibilidade de uma agressão indesejável e ilegítima por parte do investigado, situação que redundaria no uso autorizado e legítimo da força física à superação da resistência.

A ideia estigmatizadora, em desacordo com a nobreza da função policial e as renúncias familiares e pessoais diárias de cada um desses profissionais, é fruto de: a.) deficiente aproximação com a população, b.) pouca ênfase nos trabalhos sociais conjuntos; e c.) fraca política institucional de valorização dos recursos humanos.

O resultado da pouca compreensão da ostensividade do trabalho policial, conjugado com ideias estigmatizadoras da respectiva função, levam ao etiquetamento (CASTRO, 1983, pp. 96-99) da diligência policial em repartições públicas e escritórios, como se fossem "invasões", antidemocráticas ou mesmo violadoras de prerrogativas profissionais, parlamentares ou dos Poderes Públicos. Antes do julgamento de eventual ação penal, o cumprimento do Mandado de Busca e Apreensão (MBA) passou pelo crivo inicial judicial e pela opinião do Ministério Público (MP) e, após cumprido, pelo prejulgamento popular, por uma série de julgamentos de Habeas Corpus (HC) e liminares e por uma cadeia de preconceitos alimentados pelos investigados, simpatizantes, militantes partidários, órgãos e associações de classe.

A busca e apreensão em repartição pública não é, pois, uma medida de fácil execução. Problemática, costuma gerar desconforto nas relações interinstitucionais.

Para ilustrar a problemática, diga-se que inexiste previsão no Código de Processo Penal, que, de tão antigo, discorre apenas que "a busca será domiciliar ou pessoal". Não é culpa do nosso CPP, mas da criminalidade organizada brasileira que evolui muito rápido, enquanto instituições e legislações se tornam obsoletas na mesma velocidade. Naqueles tempos, não se imaginava a figura da "pessoa jurídica delinquente" e que espaços públicos pudessem ser utilizados para ocultação e cometimento de crimes e para o enriquecimento pessoal (não o enriquecimento pessoal 
pelo trabalho, mas aquele outro, o do enriquecimento pessoal pelo recebimento ou exigência de vantagens indevidas).

Os atos normativos das Polícias Judiciárias, em geral, se limitam a recomendar que a busca em repartições públicas, quando necessária, seja antecedida de contato com o dirigente do órgão, onde será realizada. Mesmo esse contato, em nome de uma política de boa vizinhança e de harmonia, merece várias considerações.

Recomenda-se que a busca e apreensão só seja comunicada ao órgão público se o alto escalão ou administração superior do órgão não estiver envolvida, sequer por omissão, com o cometimento de crimes e essa hipótese, ainda que remota, tenha sido descartada de plano pela equipe de investigação, com absoluta segurança.

A comunicação, que seria prévia à diligência, mas não sem adoção de cautelas legais e operacionais, ocorrerá: a.) tão somente depois de a equipe policial chegar ao local; b.) quando assegurada a segurança do perímetro; c.) verificado se há pessoas na repartição ou imediações que possam comprometer a colheita de provas e indícios; d.) com anuência do Poder Judiciário e do Ministério Público, devendo constar a circunstância de comunicação ao dirigente do órgão na representação policial.

Em síntese, a comunicação ocorrerá só depois que adotadas todas as medidas para que não haja contaminação na produção e colheita das provas, neutralizando possível iniciativa do investigado que possa interferir no resultado útil da diligência. A partir daí, é razoável a comunicação da diligência ao dirigente da repartição pública, representante da administração superior do órgão ou seu preposto, que deverá franquear o acesso aos diversos andares, salas, gavetas, computadores, câmeras de circuito interno, com o menor impacto possível na atividade diária da repartição, por analogia ao art. 248 do CPP.

Uma boa prática é aguardar, por prazo razoável, segundo o prudente critério do Delegado de Polícia, a chegada do preposto ou representante do órgão público para se iniciar a diligência, a fim de que possa acompanhar a lisura do procedimento. É claro que a presença de representante do órgão não é exigência legal, aperfeiçoando-se a diligência com o acompanhamento de testemunhas que assinarão o auto circunstanciado (art. 245, $\$ 1^{\circ}$ do CPP). 
Na redação final do projeto de Lei do Senado no 156/2009 (anexo ao Parecer no 1636/2010), persiste a falta de disciplina da busca e apreensão em repartições públicas, empresas e escritórios de profissionais liberais, repetindo-se as disposições do vetusto CPP. Peca, ainda, por não contemplar medidas singelas como: a.) disciplina da leitura e entrega de segunda via ou contrafé de mandado de busca e apreensão; b.) faculdade de backup da mídia apreendida e documentos, no caso de sua apreensão; c.) fornecimento de uma via do auto de apreensão ou de arrecadação; d.) explicitação de acompanhamento das testemunhas em cada compartimento ou dependência do local; e.) necessidade de lacrar o local arrombado, principalmente quando abandonado ou não habitado.

Ainda no PLS no 156/2009, a medida cautelar, que é basicamente preparatória da ação penal, continua sendo tratada após a citação e intimações, quando melhor estaria na parte inicial do CPP, logo após a disciplina da decisão proferida pelo juiz de garantias, que é o responsável pela análise, mitigação e afastamento das garantias constitucionais.

É aplicável a Portaria $n^{\circ} 1.287 / 2005-M J$, especialmente no que diz respeito a que "não se fará a apreensão de suportes eletrônicos, computadores, discos rígidos, bases de dados ou quaisquer outros repositórios de informação que, sem prejuízo para as investigações, possam ser analisados por cópia (back-up) efetuada por perito criminal federal especializado" (art. $3^{\circ}$ ).

Por fim, uma última observação a respeito da busca em repartições públicas. A diligência, naturalmente, poderá acontecer com a concorrência de outros órgãos públicos parceiros, como a Controladoria-Geral da União (fraudes em processos licitatórios em Prefeituras) e Ministério da Previdência Social, por sua Assessoria de Pesquisas Estratégicas (fraudes previdenciárias na concessão de benefícios em agências do INSS), por exemplo, em razão do conhecimento técnico especializado de seus auditores e técnicos, que auxiliarão a equipe policial na triagem do material a ser apreendido, inclusive na de processos físicos e eletrônicos que possam constituir corpo de delito.

Nesta clara situação de parceria e apoio interinstitucional, que reflete a imprescindibilidade do trabalho em equipe, os servidores e colaboradores não policiais devem se deslocar por meios próprios fornecidos pela instituição de origem, evitando-se o deslocamento em viaturas policiais, o que pode fragilizar a sua segurança ao invés de aumentá-la, numa situação de 
perseguição em alta velocidade ou ação criminosa contra policiais. A presença do corpo técnico não policial, no local de busca, será consignada no auto circunstanciado, assim como a presença eventual do representante do $\mathrm{Mi}$ nistério Público. É recomendável que pessoas alheias à diligência funcionem como testemunhas do cumprimento do mandado judicial.

\section{O Modus Operandi da Diligência de Busca e Apreensão}

A operação policial deve contemplar, além das disposições legais, recomendações consentâneas com o império do Direito (DWORKIN, 2007, pp. 9-11), para que a diligência correspondente seja executada: a.) de forma circunstanciada, de tudo lavrando-se auto; b.) com cortesia, harmonia, transparência e discrição; c.) com proatividade da equipe; d.) observada a discrionariedade regrada pelo interesse público e pelos instrumentos legais e normativos; e.) de forma eficaz, eficiente, proporcional e razoável; f.) com uso excepcional e progressivo da força nas situações que a legitimem; g.) sem constrangimentos que não sejam os decorrentes do cumprimento da lei e do mandado judicial; h.) em parceria ou regime de força-tarefa com as demais instituições; i.) de forma sigilosa, sendo que a política de comunicação social do órgão policial deve se pautar pelo interesse público e pela preservação dos direitos dos investigados, inclusive o de imagem.

Quanto ao exposto na letra "i", é de capital importância o art. $201^{1}$ da recente Instrução Normativa (IN) no $1 / 2015$ da Polícia Civil do Estado do Paraná (PC/PR):

Art. 201. Os Delegados de Polícia deverão abster-se da divulgação, pelos órgãos de comunicação, de imagens de pessoas tidas como suspeitas ou indiciadas em inquéritos policiais, face aos principios estatuidos nos incisos X, XLI, XLIX e LVII, do art. $5^{\circ}$ da Constituição Federal, arts. $1^{\circ}, 2^{\circ}$ e $3^{\circ}$, parágrafo único do Decreto Estadual $n^{\circ}$ 465 de 11 de junho de 1991, Ordem de Serviço 14/2014, do Departamento da Policia Civil, salvo quando por elas expressamente autorizadas, a critério e sob responsabilidade do Delegado de Policia encarregado da investigação.

1 Disponívelem:http://www.corregedoriapoliciacivil.pr.gov.br/arquivos/File/INSTRUCOES/2015/ IN_01_2015_B.pdf. Acesso em 5 ago. 2016. 
Some-se às orientações contidas nas letras "a" a "i” um extenso rol normativo disciplinador do cumprimento do mandado de busca e apreensão ${ }^{2}$ : artigo $5^{\circ}$ da Constituição Federal (CF), dos artigos 240 a 250 do Código de Processo Penal (CPP), da Lei 8.906/94, das Portarias 1.287 e 1288-Ministério da Justiça - MJ (Diário Oficial da União -DOU I, de 1 de julho de 2005), da IN 11/2001-DG/DPF (DOU I, de 2 de julho de 2001, em vias de revisão e atualização).

\section{Dispensabilidade do Mandado de Busca e Apreensão quando Efetuada a Prisão em Flagrante}

Põe-se em análise a eventual necessidade de mandado de busca e apreensão em situações flagranciais de ocorrências criminais.

$\mathrm{Na}$ esteira do pensamento dos Tribunais superiores, em caso de prisão em flagrante, dispensa-se o mandado de busca e apreensão:

(...) 1. Este Tribunal Superior prega que, por ser permanente o crime de tráfico de drogas, a sua consumação se protrai no tempo, de sorte que a situação de flagrância configura-se enquanto o entorpecente estiver sob o poder do infrator, sendo possivel, portanto, em tal hipótese, o ingresso da polícia na residência, ainda que não haja mandado de prisão ou de busca e apreensão, já que incide a excepcionalidade inscrita no art. $5^{\circ}$, inciso XI, da CF, a afastar a inviolabilidade do domicílio.

2. Outrossim, não há falar em vício na operação policial, se houver a permissão de entrada dos policiais na residência do investigado, a descaracterizar a inviolabilidade de domicílio, que pressupóe, justamente, o não consentimento do morador. (...) (HC 208.957/SP, Rel. Desembargador convocado Vasco della Giustina, 6a. T. do STJ, DJe 19/12/2011).

(...) 2. Estando o agente em situação de flagrante delito, tornam-se desnecessários para acesso ao seu domicílio, o mandado de busca e apreensão judicialmente autorizado, bem como o consentimento do morador. (AgRg no Ag 1357515/DF, Rel. Min. Jorge Mussi, $5^{a}$ T. do STJ, DJe 26/08/2011).

No âmbito da PF o trato normativo dado pela Instrução Normativa n. 11/01-DG/PF é semelhante:

2 GOMES, Rodrigo Carneiro. Disponível em: http://www.jf.jus.br/ojs2/index.php/revcej/article/ viewFile/741/921. Acesso em 5 ago. 2016. 
66. O ingresso em casa, sem consentimento do morador, somente poderá ocorrer nas hipóteses de flagrante, desastre ou para prestar socorro, conforme previsão do inciso XI do art. $5^{\circ}$ da Constituição Federal.

66.1. No caso de consentimento do morador a busca será presenciada por duas testemunhas não policiais, que assinarão o respectivo auto, além do termo de consentimento de busca.

O termo de consentimento do morador é tranquilamente aceito pelos tribunais:

(...) O consentimento do morador supre a determinação judicial para o ingresso em residência, não havendo qualquer exigência de que tal consentimento deva ocorrer na presença de testemunhas do povo. (HC 18.863/DF, Rel. Min. Gilson Dipp, 5a. T do STj3).

Recentemente, no julgamento do Recurso Extraordinário (RE) $n^{\circ}$ 603616, com repercussão geral, o STF, por maioria de votos, firmou a tese de que "a entrada forçada em domicílio sem mandado judicial só é lícita, mesmo em período noturno, quando amparada em fundadas razões, devidamente justificadas a posteriori, que indiquem que dentro da casa ocorre situação de flagrante delito, sob pena de responsabilidade ... do agente e de nulidade dos atos praticados".

O julgado estabelece a tese da justa causa para a entrada domiciliar sem mandado judicial, contudo, embora divulgada pelo site ${ }^{4}$ de notícias do STF, como um avanço na orientação jurisprudencial do STF, a Polícia Judiciária sempre se orientou pela necessidade de indícios razoáveis para a entrada domiciliar para situação noticiada, por fonte revestida de credibilidade que relate a flagrante ocorrência de um crime no local. O que será alterado na rotina policial é o aperfeiçoamento do registro das notícias de ocorrência de um crime em curso ou sua permanência, ou seja, em caso de dúvida razoável quanto à legalidade da ação policial, esse será instado a justificar de onde partiu a informação que levou à prisão em flagrante delito e suas circunstâncias, o que, de certa forma, já é esclarecido ao tempo da lavratura do auto de prisão em flagrante delito.

3 DJ 16/09/2002, p. 207.

4 Disponível em http://www.stf.jus.br/portal/cms/verNoticiaDetalhe.asp?idConteudo=303364\&cai xaBusca $=$ N. Acesso em 5 ago. 2016. 


\section{DA PRÉVIA INSTAURAÇÃO DE INQUÉRITO E FORMALIZAÇÃo DOS ATOS DE POLÍCIA JUdICIÁRIA COMO REQUISITOS PARA O MANDADO DE BUSCA E APREENSÃO}

Em princípio, ressalvada a apuração de situação flagrancial que não possibilite a imediata instauração de procedimento policial, a representação por mandado de busca e apreensão e demais medidas cautelares ocorrerá em inquérito preexistente, o qual, quando possível, mencionará na portaria inicial, subscrita pelo Delegado de Polícia, a delimitação do fato, sua tipicidade penal e possível autoria.

As medidas cautelares, a exemplo da representação por MBA, serão apensadas ao inquérito após o levantamento de sigilo judicial e quando não sejam mais consideradas pendentes ou "em andamento", não sendo possível o acesso "à decretação e às vicissitudes da execução de diligências em curso" (HC 82354/PR, Rel. Min. Sepúlveda Pertence, $1^{\text {a }}$ Turma do STF5). No AgR Rcl no 18.191, Rel. Min. Roberto Barroso, a $1^{\text {a }}$ Turma do $S T F^{6}$ não autorizou o acesso à interceptação telefônica "sob o fundamento de ainda estarem em curso as diligências. 2. Em razão da natureza sigilosa do feito, bem como da não conclusão de diligências, não há ofensa à Súmula Vinculante 14".

É fundamental a prévia formalização ou documentação dos atos de polícia judiciária executados e determinados, inclusive cautelares pois, embora o inquérito seja sigiloso, o ordenamento jurídico pátrio não compactua com investigações secretas, assim, essas não se iniciam e não se encerram sem atos formais, justamente para que não fiquem na esfera subjetiva do investigador. Equipes policiais, salvo apurações urgentes de delitos em curso, diligenciam mediante ordens de missão policiais (OMP) ou de serviço expedidas em sede de procedimento policial (inquérito, termo circunstanciado, verificação de procedência de informação com notícia-crime registrada nos sistemas policiais), com apresentação de relatório circunstanciado após prazo determinado.

Da IN no 1/2015-PC/PR, destaca-se:

Art. 197. Sendo o inquérito policial um instrumento que registra a atividade de polícia judiciária, a atuação do servidor policial há

5 DJ de 24/09/2004.

6 DJe-107, 05-06-2015. 
que ter sempre o respaldo de uma ordem de serviço expedida pelo Delegado de Policia, em face do caso concreto, exceto nos casos de flagrante delito.

$\mathrm{O}$ artigo 2 da IN no 5/2000-DG/DPF, reproduzido nos artigos 6 e 28 da IN no $1 / 2013-\mathrm{PC} / \mathrm{BA}$, pontua que a OMP "é documento de natureza policial de caráter sigiloso, de uso interno, obrigatório em qualquer missão de policiais federais, expedido por autoridade competente".

A formalidade do ato de investigação é exigência legal e constitucional, garantindo-se ao investigado, desde o ato de prisão: a.) o direito de comunicar-se com familiares e advogado; b.) o direito de não se autoincriminar (fornece-se nota de ciência das garantias constitucionais); c.) a identificação dos responsáveis por sua prisão ou por seu interrogatório policial (art. $5^{\circ}$, incisos XLIX, LXI a LXVI da CF); d.) nota de culpa (art. 306, $\$ 2^{\circ}$ do CPP); e.) comunicações ao Poder Judiciário, MP (art. 306 do CPP), Defensoria Pública (na ausência de advogado constituído), Consulado ou Embaixada, Funai (índio não integrado), MJ (caso de abertura de inquérito de expulsão de estrangeiro); f.) ofícios para realização de exame de integridade física do preso (ad cautelam), de seu encaminhamento ao sistema prisional.

A investigação policial não é formada apenas pelos atos escritos do Delegado de Polícia como a portaria (ato inicial), decisão fundamentada de prisão e de indiciamento, despacho de impulso da investigação, representações por medidas cautelares (como a de busca e apreensão) de afastamento ou mitigação de garantias constitucionais e o relatório (ato final), mas por uma coletividade de iniciativas e diligências executadas por todos os policiais envolvidos.

O delegado e o escrivão de polícia e igualmente o agente de polícia, inspetor ou investigador (que atua como olhos, ouvidos, voz, braços e pernas da autoridade policial, em diligências externas) são responsáveis por atos formais no inquérito. Cabe ao agente, por exemplo, a confecção de informações, autos circunstanciados, relatórios de missão policial (RMP), de análises e de vigilância, que, se não forem bem lavrados e diligenciados com proatividade, levarão ao retardo, fracasso da investigação ou frustração do objeto do MBA. A equipe policial deve ser boa e competente tanto na linha de tiro como na caneta, no tablet, no computador e na consulta de sistemas informatizados, afinal de contas, o sucesso da investigação e a celeridade do inquérito são resultados de um trabalho em equipe. 
Retomando o tema, ainda quanto à formalização dos atos de polícia judiciária - que é uma decorrência lógica também da Súmula Vinculante 14 do STF, para que o advogado possa ter acesso aos documentos já produzidos para atuar em defesa de seu cliente -, o excelso STF já manifestou que eventual investigação pelo MP deverá observar o rol de direitos constitucionais do investigado e conterá todas as peças, termos de declarações e demais subsídios probatórios coligidos:

O procedimento investigatório instaurado pelo Ministério Público deverá conter todas as peças, termos de declaraçóes ou depoimentos, laudos periciais e demais subsidios probatórios coligidos no curso da investigação, não podendo, o Parquet, sonegar, selecionar ou deixar de juntar, aos autos, quaisquer desses elementos de informação, cujo conteúdo, por referir-se ao objeto da apuração penal, deve ser tornado acessivel tanto à pessoa sob investigação quanto ao seu Advogado. - O regime de sigilo, sempre excepcional, eventualmente prevalecente no contexto de investigação penal promovida pelo Ministério Público, não se revelará oponivel ao investigado e ao Advogado por este constituido, que terão direito de acesso - considerado o princípio da comunhão das provas - a todos os elementos de informação que já tenham sido formalmente incorporados aos autos do respectivo procedimento investigatório. (HC 94173, Rel. Min. Celso de Mello, $2^{a}$ T. do STF, DJe-223, 27-11-2009).

Ou seja, em razão dos gravames que lhes são inerentes, toda e qualquer medida cautelar invasiva da intimidade do cidadão e investigação criminal que se inicie - seja qual for o nome que a ela se dê ou roupagem, de iniciativa do MP ou da Polícia Judiciária -, assegurará ao investigado os seus direitos e se revestirá de forma escrita, como garantia de não haver atos secretos e nem subjetivismo do investigador.

\section{5. "Capacidade Postulatória" na Representação por MANDAdo de Busca e Apreensão}

O tema "busca e apreensão" comporta inúmeras peculiaridades que continuarão sendo tratadas nesta oportunidade.

Tem-se observado uma tendência coordenada de alguns setores do Ministério Público (MP) ao se manifestar a respeito das representações por medidas cautelares do Delegado de Polícia, em negar-lhes validade em razão da falta de "capacidade postulatória" ou legitimidade do representante. 
Em nome do interesse público, contudo, o órgão ministerial passa a adotá-las e subscrevê-las ao Poder Judiciário. Propaga-se, assim, o sofisma da "falta de capacidade postulatória" segundo o qual a Polícia Federal não pode bater na porta do Poder Judiciário. A estratégia, viciada constitucionalmente, apresenta inúmeras falhas de construção, destacando-se a usurpação da cláusula de reserva de jurisdição, do direito ao acesso e petição aos Poderes Públicos.

A competência do Poder Judiciário para decidir conflitos administrativos, na fase pré-processual, não passou despercebida na decisão monocrática no Agravo de Instrumento no 5032332-92.2014.404.0000/RS, Relatora Juíza Convocada Simone Barbisan Fortes, TRF-4a Região, conforme noticiado pela imprensa ${ }^{7}$ :

(...) os inquéritos policiais, mesmo na hipótese de tramitação direta, devem ser remetidos à Justiça (...), independentemente da necessidade de medidas constritivas, mormente tocantes à definição de sua futura competência (...) mesmo em casos de tramitação direta do inquérito entre a polícia e o Ministério Público, está a autoridade policial autorizada a peticionar diretamente ao Juizo, em tudo quanto disser respeito a providências úteis ou necessárias ao andamento procedimental que conduzirá a um julgamento (...). (Negritou-se).

$\mathrm{O}$ aresto confirmou, em parte, a decisão judicial, nos seguintes termos:

DIREITO PROCESSUAL PENAL. INQUÉRITO POLICIAL. PRERROGATIVAS DA POLÍCIA FEDERAL E DO MINISTÉRIO PÚBLICO FEDERAL. MANIFESTAÇÃO SOBRE A COMPETENCIA. POSSIBILIDADE. REQUISIÇÃO DE NOVAS DILIGENNCIAS. CUMPRIMENTO. FASE PRÉ-PROCESSUAL NÃO ENCERRADA.

1. As prerrogativas dos membros da Polícia Federal e do Ministério Público são complementares e devem ser compreendidas à vista dos interesses da sociedade, de modo a que se obtenha a maior abrangência e a maior efetividade das atividades investigativas.

2. O Delegado de Polícia Federal, ao elaborar o relatório final do inquérito policial, tem a prerrogativa de se manifestar sobre os pontos que lhe pareçam relevantes, inclusive quanto à competência, o que não vincula, por certo, o Ministério Público Federal.

7 Disponível em: http://fenadepol.org.br/reconhecida-a-capacidade-postulatoria-do-delegado-depolicia-federal. FAUSTO, Macedo. Justiça reconhece capacidade postulatória de delegados da PF. Disponível em: http://politica.estadao.com.br/blogs/fausto-macedo/justica-reconhece-capacidadepostulatoria-de-delegados-da-pf. Acesso em 5 ago. 2016. 
Cite-se outro precedente judicial da Subseção Judiciária de Manhuaçu/MG, TRF-1 ${ }^{\text {a }}$ Região, Processo no 1458-22.2013.4.01.3819²: "é preciso registrar que o Delegado de Polícia, na qualidade de presidente do inquérito policial, tem, sim, legitimidade para postular as medidas cautelares que entender pertinentes ao sucesso das investigações".

Lamentavelmente, às vezes o óbvio precisa ser objeto de provocação e decisão judicial. Fato é que não há titularidade da ação penal na fase inquisitiva, cabendo ao Delegado de Polícia a condução regular do inquérito, sob sua coordenação e responsabilidade, não sendo a manifestação ministerial vinculativa da atividade policial ou judicial.

No RE no 593727, a Ministra Rosa Weber do STF, anotou, com muita propriedade:

Reconhecer o poder de investigação do Ministério Público em nada afeta as atribuiçôes da polícia e não representa qualquer diminuição do papel relevantíssimo por ela conduzida. As melhores investigaçôes decorrem de atuação conjunta, um contribuindo para a atividade do outro.

Em princípio, o Exmo. Procurador-Geral da República teria se manifestado ${ }^{9}$, ao final do julgamento do RE no 593727, no sentido de que os dois órgãos devem atuar de modo "cooperado" e que "Não se quer aqui estabelecer cisão entre Ministério Público de um lado e polícia de outro. O que se quer é a cooperação de ambos. Não se trata aqui de estabelecer o trabalho de um contra o do outro".

Contudo, em que pese as palavras conciliatórias do dirigente máximo do MP, a tendência excludente das representações policiais evoluiu para a edição da Orientação n ${ }^{\circ}$ 04/2014 $4^{10}$, da $7^{\text {a }}$ Câmara de Coordenação e Revisão do MPF, que "orienta os Membros do Ministério Público Federal a, respeitada a independência funcional, pugnarem pelo não conhecimento do pedido de medida cautelar formulado por autoridade policial diretamente ao Juízo".

8 Disponível em: http://www.conjur.com.br/2014-fev-04/policia-nao-autorizacao-mpf-solicitarapreensao. http://s.conjur.com.br/dl/policia-nao-autorizacao-mpf-solicitar.pdf. TEIVE, Renato Silvy. Capacidade postulatória do delegado de polícia. Disponível em: http://www.jurisway.org.br/ v2/dhall.asp?id_dh=14495. Acesso em 5 ago. 2016.

9 Disponível em: http://g1.globo.com/politica/noticia/2015/05/stf-confirma-poder-de-investigacaodo-ministerio-publico.html. Acesso em 5 ago. 2016.

10 Disponível em: http://www.pgr.mpf.mp.br/conheca-o-mpf/estrutura/corregedoria/AtoseNormasAGOSTO-2015.pdf. Acesso em 5 ago. 2016. 
A orientação subsequente (Orientação no 05/2014) ${ }^{11}$, corroborando a recomendação para que não seja conhecida a representação cautelar da Polícia Federal, menciona que não cabe à PF formular qualquer petição diretamente ao Poder Judiciário:

considerando a ausência de capacidade postulatória das autoridades policiais, às quais não cabe formular petições diretamente aos magistrados a qualquer titulo, inclusive para promover declinios de atribuição (...) ORIENTA os membros do Ministério Público Federal, respeitada a independência funcional, a recorrerem de decisão judicial que acolha requerimento de declinio de competência formulado diretamente por autoridade policial, certo que, no tocante aos inquéritos policiais não judicializados, as questões de atribuição devem ser dirimidas no âmbito do próprio Ministério Público (...).

Enquanto a Polícia Federal tenta pacificar os ânimos e editar atos normativos e orientativos que compatibilizem a atuação conjunta com o $\mathrm{MPF}$, certas iniciativas jogam por terra todo o esforço dos órgãos públicos para que seus servidores entendam a importância do trabalho integrado no sistema de justiça criminal, e permitem que prevaleça a voz desagregadora de poucos em detrimento do esforço agregador.

É claro que manifestações no sentido de impossibilidade de representação pelo Delegado de Polícia são contra legem. Contudo, o bom senso e o trabalho em conjunto prevalecem para aqueles que estão realmente interessados em dar uma resposta para a sociedade a respeito da repressão à crescente onda criminosa. Neste pequeno mundo do sistema de justiça criminal, os bons profissionais se conhecem e trabalham em conjunto e harmoniosamente.

Oportuna a lição de Borelli Thomaz $(2015)^{12}$ :

Para a efetividade da investigação, o poder postulatório do delegado poderá decorrer do exercício da representação, meio disponivel para instrumentalizar e facilitar a busca da verdade material, bem como para que seja possivel a adoção de medidas tendentes a restringir direitos e garantias individuais, como a liberdade (no caso de prisão) ou o patrimônio (no caso de sequestro de bens), ou de alguma medida jurídica que possa vir a atingir direitos da personalidade do investigado.

11 Idem.

12 THOMAZ, Thiago Hauptmann Borelli. MP pode investigar, mas delegado preside inquérito e comanda persecução. Disponível em: http://www.conjur.com.br/2015-jun-07/thiago-thomaz-mpinvestigar-delegado-preside-inquerito. Acesso em 5 ago. 2016. 
Por trás da adoção de representações policiais como se de terceiros fosse e a subjacente questão ética, há um perigoso subterfúgio para afastar o Poder Judiciário do inquérito policial, da análise das representações policiais e dos incidentes pré-processuais no inquérito. Isto é mais preocupante quando a incidência desse propósito ocorre em medidas cautelares mitigadoras de garantias constitucionais.

O tramite direto do inquérito entre o órgão policial e o ministerial, previsto na Resolução no 63/2009 do Conselho da Justiça Federal (CJF), não retira a legitimidade e legalidade da representação do Delegado de Polícia ao Poder Judiciário. A citada resolução apenas a excepcionou na dilação de prazo da investigação, por considerar que "não há exercício de atividade jurisdicional no simples deferimento de prorrogação de prazo para a conclusão das investigações policiais".

A Resolução n ${ }^{\circ} 63$ do CJF ${ }^{13}$ garante que "Havendo qualquer outro tipo de requerimento, deduzido pela autoridade policial, que se inserir em alguma das hipóteses previstas no art. $1^{\circ}$ desta resolução, os autos do inquérito policial deverão ser encaminhados ao Poder Judiciário Federal para análise e deliberação" (art. $3^{\circ}$, parágrafo único). $\mathrm{O}$ art. $1^{\circ}$ prevê a representação da autoridade policial para a decretação de prisóes de natureza cautelar; o requerimento da autoridade policial de medidas constritivas ou de natureza acautelatória; requerimento de extinção da punibilidade com fulcro em qualquer das hipóteses previstas no art. 107 do Código Penal ou na legislação penal extravagante.

A Resolução n ${ }^{\circ} 993^{14}$, de 5 de março de 2015, do Tribunal Regional Eleitoral de Minas Gerais, prevê idênticas hipóteses e acrescenta o "requerimento de declinação de competência", ao contrário do que dispõe a Orientação $05 / 2014-7^{\mathrm{a}} \mathrm{CCR} / \mathrm{MPF}$.

Independentemente do que estatui a Resolução no 63/2009-CJF, vasta legislação federal confere prerrogativa de representação pelo Delegado de Polícia ao Poder Judiciário ou de requisição de dados: artigos $6^{\circ}$, 13, IV, 127, $149, \S 1^{\circ}, 282, \$ 2^{\circ}$, 311 e 378 , II do CPP, artigo $2^{\circ}$ e seu $\$ 1^{\circ}$ e art. $3^{\circ}$., inci-

13 Disponível em: https://www2.cjf.jus.br/jspui/bitstream/handle/1234/5547/Res\%20063\%20 de\%202009.pdf. Acesso em 5 set. 2015.

14 Disponível em: http://www.justicaeleitoral.jus.br/arquivos/tre-mg-resolucao-tre-mg-no-993-de-05de-marco-de-2015. Acesso em 5 ago. 2016. 
so I, ambos da Lei $n^{\circ} 7.960 / 89$, artigo $3^{\circ}$, I, da Lei $n^{\circ} 9.296 / 96$, artigo $4^{\circ}$ e 17-b da Lei no 9.613/98, artigos 51, parágrafo único, 60, 62, $\$ 2^{\circ}$ e 72 da Lei ${ }^{\circ}$ $11.343 / 2006, \operatorname{artigo} 2^{\circ}, \S 2^{\circ}$ da Lei $n^{\circ} 12.830 / 2012$, artigos $4^{\circ}, \S 2^{\circ}, 10$ a 12 e 21 da Lei $n^{\circ} 12.850 / 2013$, artigos $13, \S 2^{\circ}$ e $15, \S 2^{\circ}$ da Lei $n^{\circ} 12.965 / 2014$.

No aspecto "capacidade postulatória" e legitimação para representar por busca e apreensão e outras medidas cautelares, urge a sensata intervenção do magistrado, em nome de uma justa e imparcial persecução criminal, para pacificar e disciplinar a digna atuação conjunta dos órgãos policiais e ministeriais, afastando-se qualquer pretensão de impedir o amplo acesso ao Poder Judiciário, amordaçar, isolar e cercear o manejo de instrumentos regulares de investigação criminal pela Polícia Judiciária.

\section{CONCLUSÃ̃o}

A maior conscientização da população, o jornalismo investigativo e a especialização e integração dos órgãos públicos encarregados da apuração de crimes de corrupção, atos de improbidade e desvio de recursos públicos têm propiciado ricas investigações de natureza administrativa ou criminal.

Os órgãos de segurança pública avançaram muito, nas últimas décadas, no planejamento operacional, nas novas estratégias para lidar com a criminalidade, nos estudos de análise criminal (mancha criminal), na revelação de cifras negras (subnotificação de crimes) e criação de centros de estudo da violência em Academias de Polícia. Houve, enfim, a evolução da tecnologia, política e sistema de segurança pública, muito embora os problemas de recursos humanos e logísticos pareçam crônicos e sem a devida priorização pelos gestores.

Nesse contexto, a visão e a técnica investigativa também se apuraram e se passou a enxergar que, relacionado a algumas modalidades criminosas específicas, como aquelas contra a Administração Pública, contra a regularidade das licitações, crimes financeiros e lavagem de dinheiro, há um braço instrumental e viabilizador da empreitada criminosa que se vale, indevidamente, não apenas da proteção constitucional domiciliar, mas também de espaços públicos e privados, para se preservar ou ocultar o corpo de delito, o que acontece, na maior parte dos casos, sem o conhecimento e participação de seus pares, sócios ou colegas de trabalho. 
O regramento jurídico estabelece um conjunto de regras para o cumprimento de mandado de busca e apreensão seja em residência, escritórios, empresas e repartições públicas, a ser observado pela Polícia Judiciária, ao qual deve ser somada a expertise policial e as precauçóes de natureza operacional, que geram recomendações adicionais.

Ressalvadas as verificações de procedência de informação para apuração de denúncias anônimas e notícias-crime desacompanhadas de elementos mínimos para iniciar uma investigação, as diligências policiais, em geral, e o cumprimento de mandados judiciais e as representações por medidas cautelares por Delegados de Polícia serão feitas mediante prévia instauração de inquérito policial.

Rodrigo Carneiro Gomes

Delegado da Polícia Federal, mestre em Direito pela UniVERSIDAde CATÓlica de BRASília, eSPECIALISTA EM SEGURANÇA PÚBliCA E DEFESA SOCIAL E PROFESSOR DA ACADEMIA NACIONAL DE Polícia..

E-MAIL:DPFCARNEIRO@GMAIL.COM

\title{
The Procedural Incidents in Search and SEIZURE: PRELIMINARY ESTABLISHMENT OF THE INVESTIGATION AND CAPACITY TO REPRESENT FOR THE PRECAUTIONARY MEASURES
}

\begin{abstract}
The enforcement of search warrant and seizure by the police must observe legal norms, normative acts and the experience acquired in the daily life, with preservation of the rights and guarantees of the citizen. Preliminary police investigation to carry out the precautionary measures of search and seizure is indispensable, and the Chief of Police is empowered to act before the Judiciary.
\end{abstract}

KEYWORDS: Search and seizure. requirements. Prison in the act. Dispensability of the arrest warrant. Chief police officer. Request. 


\title{
Incidentes Procedimentales en la Búsqueda Y Aprehensión: instauración PREVia de La INVESTIGACIÓN POLICIAL Y CAPACIDAD PARA REPRESENTAR POR LAS MEDIDAS CAUTELARES
}

\begin{abstract}
RESUMEN
La diligencia policial que cumple el orden judicial de búsqueda y aprehensión debe observar las normas legales, las disposiciones normativas y la experiencia de la vida cotidiana, esto con objetivo de preservar los derechos y garantías de los ciudadanos. Es indispensable la instauración previa de la investigación policial para la aplicación de medidas precautorias de búsqueda y aprehensión, y es del jefe de la policía el poder de actuar ante el poder judicial.
\end{abstract}

Palabras Clave: Búsqueda y Aprehensión. Requisitos. Detención en flagrante. Prescindible de la orden de detención. Jefe de la Policía. Aplicación.

\section{REFERÊNCIAS}

BACILA, Carlos Roberto. Estigmas: um estudo sobre os preconceitos. Rio de Janeiro: Lumen Juris, 2005.

CASTRO, Lola Anyar de. Criminologia da reação social. Rio de Janeiro: Ed. Forense, 1983.

DUTRA, Luciano. Busca e apreensão penal - da legalidade às ilegalidades cotidianas. Porto Alegre: Conceito, 2010.

DWORKIN, Ronald. O império do direito. São Paulo: Martins Fontes, 2007.

GOMES, Rodrigo Carneiro. Contornos do mandado de busca e apreensão. Disponível em: http://www.jf.jus.br/ojs2/index.php/ revcej/article/viewFile/741/921. Acesso em 5 ago. 2016.

GRINOVER, Ada Pellegrini. Novas tendências do direito processual. Rio de Janeiro: Forense Universitária, 1990.

LOPES JUNIOR, Aury. Direito Processual Penal e sua conformidade constitucional, vol. I. Rio de Janeiro: Lúmen Juris, 2011. . Direito Processual Penal. São Paulo: Saraiva, 2014. 
MIRABETE, Julio Fabbrini. Código de Processo Penal - Interpretado. São Paulo: Atlas, 2001.

PERAZZONI, Franco; SILVA, Wellington Clay Porcino. in Inquérito Policial: um instrumento eficiente e indispensável à investigação. Revista Brasileira de Ciências Policiais Brasília, v. 6, n. 2, p. 77115, Edição Especial - jul/dez, 2015.

PITOMBO, Cleunice Bastos. Da busca e apreensão no processo penal. São Paulo: RT, 2005.

TEIVE, Renato Silvy. Capacidade postulatória do delegado de polícia. Disponível em: http://www.jurisway.org.br/v2/dhall.asp?id_ $\mathrm{dh}=14495$. Acesso em 5 ago. 2016 .

THOMAZ, Thiago Hauptmann Borelli. MP pode investigar, mas delegado preside inquérito e comanda persecução. Disponível em: http://www.conjur.com.br/2015-jun-07/thiago-thomaz-mpinvestigar-delegado-preside-inquerito. Acesso em 5 ago. 2016. 